\title{
Analysis of Pharmacokinetic \& Pharmacodynamic Models in Oral and Transdermal Dosage Forms
}

\section{Parthasarathi $D^{1 *}$, Gajendra $C^{1}$, Dattatreya $A^{2}$ and Sree Venkatesh $Y^{3}$}

${ }^{1}$ Department of Biotechnology \& Bioscience, Fakir Mohan University, Balasore, Odisha, India

${ }^{2}$ GITAM Institute of Sciences, GITAM University, Visakhapatnam, Andhrapradesh, India

${ }^{3}$ Biotechnology Department, Andhra University, Visakhapatnam, Andhrapradesh, India

\begin{abstract}
Bioavailability is a pharmacokinetic term which refers the extent and speed of absorption of the chemicals content in it. After the absorption the drug plays the important role in which the body react i.e. the pharmacodynamics process. Oral drugs, Transdermal drugs, Lipophilic drugs and combined oral drugs all plays the different role after being absorbed and the mode of absorption is also different through various research. The pharmacokinetic parameters $(A \cup C),\left(C_{\max }\right)$ and dynamic models express the process of drug ADME reports. Various sample analysis is also being done through various instrumentation and databases. Researches and reports reveal the various side effects of few drugs which are taken orally as well as transdermally and the combine effects are being taken into consideration. The main aim is to analyze the process of drug absorption through various parameters, different instruments and mention the side effects after absorptions.
\end{abstract}

Keywords: Pharmacokinetics; Pharmacodynamics; Oral drugs; Transdermal; Bioavailability; Bioequivalence; Lipophilic

\section{Introduction}

Pharmacokinetic studies is based on a traditional intensive design model which usually conducted using carefully selected volunteer subjects, a controlled experimental design, and collection of multiple blood samples [1]. Measurements of drug and metabolite with pharmacokinetic models determine parameters like elimination halflife, volume of distribution, and clearance which is also known as Bioavailability. It is a pharmacokinetic term that describes the rate and extent to which the drug ingredient is absorbed from a drug product and becomes available in the systemic circulation [2]. Bioavailability is also a pharmaceutical form refers to the extent and speed of absorption of the active principle contained in it [3]. But studies assess the relative fraction of the orally administered dose that is absorbed into the systemic circulation when compared to the bioavailability data for a solution, suspension, or intravenous dosage form and provide pharmacokinetic information related to distribution, elimination, effects of nutrients on absorption of the drug, dose proportionality, linearity in pharmacokinetics of the active moieties and appropriate inactive moieties [4]. Rather Bioavailability of drug depend upon the gastric emptying time, $\mathrm{pH}$ of the stomach, rate of metabolism and other individual variations for the pharmacokinetic pathway inside the body, these characteristics plays a very minor role [5]. Some drugs are too painful such as diagnosis and therapeutic approaches for pediatric cancer; in this approach analgosedation is performed under intensive care. Prophylactic approaches used to acute the side effects [6].

Similarly, Bioequivalence studies are to demonstrate bioequivalence between a pharmaceutically equivalent generic drug product and the corresponding drug. Together with the determination of pharmaceutical equivalence, establishing bioequivalence allows a regulatory conclusion of therapeutic equivalence. Bioequivalence studies compare the systemic exposure profile of a test drug product to that of a reference drug product. Two pharmaceutical forms are said bioequivalent when, the drug being administered to the same individual, in the same experimental conditions and at the same dose, showed no significant differences in relation to bioavailability [7]. This studies are important in the development of inhaled medications and delivery devices.
For inhaled medications, bioequivalence ensures that equal doses of different agents of the same class, or different formulations of the same medication (i.e. powdered or aerosolized), produce equivalent pharmacodynamics effects [8]. Pharmacodynamics is the study of the biochemical and physiological effects of drugs on the body or on microorganisms or parasites within or on the body and the mechanisms of drug action and the relationship between drug concentration and effect [9]. Its clinical efficacy studies are considered the most useful tool to assess bioequivalence of different inhaled medications or different inhalation devices [8]. Pharmacodynamics is often summarized as the study of what a drug does to the body, whereas pharmacokinetics is the study of what the body does to a drug [9].

\section{Pharmaco-kinetic-dynamic model}

Pharmacokinetics is the discipline that applies mathematical models to describe and predict the time course of drug concentrations in body fluids, whereas pharmacodynamics refers to the time course and intensity of drug effects on the organism, whether human or experimental animal. Both evolve a technique for measuring the drug concentration to accurate and sensitive way. A kinetic-dynamic study in clinical psychopharmacology typically involves medication administration (usually under placebo-controlled, double-blind laboratory conditions) followed by quantitation of both drug concentration and clinical effect at multiple times after dosing. Pharmacokinetic and pharmacodynamics relationship evaluates separately and later its evaluation is recorded graphically as well as mathematically [1]. Bioavailability and Bioequivalence may be determined using both plasma concentrations

*Corresponding author: Parthasarathi D, Department of Biotechnology \& Bioscience, Fakir Mohan University, Balasore, Odisha, India, E-mail: parthasarathi5ds@ yahoo.co.in

Received November 15, 2011; Accepted December 03, 2011; Published December 05, 2011

Citation: Parthasarathi D, Gajendra C, Dattatreya A, Sree Venkatesh Y (2011) Analysis of Pharmacokinetic \& Pharmacodynamic Models in Oral and Transdermal Dosage Forms. J Bioequiv Availab 3: 268-276. doi:10.4172/jbb.1000098

Copyright: $(2011$ Parthasarathi $D$, et al. This is an open-access article distributed under the terms of the Creative Commons Attribution License, which permits unrestricted use, distribution, and reproduction in any medium, provided the original author and source are credited. 


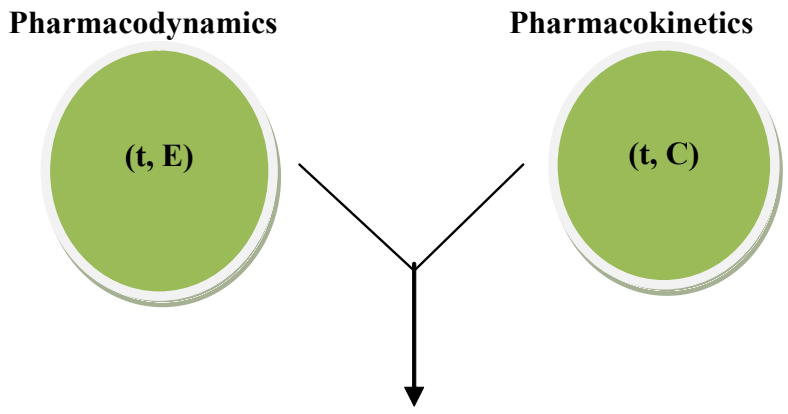

Pharmaco-kinetics-dynamic model

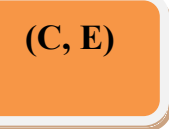

Figure 1: Denotes the correlation of Pharmacodynamics \& Pharmacokinetic model where't'-time interval of the measurement process

of a drug (pharmacokinetic parameters) and its pharmacological effects (pharmacodynamics parameters). However, drug concentrations(C) in blood/plasma, the active site or the peripheral compartment and the pharmacological effects (E) often follow a non-linear relationship, known as the Hill equation (equation below). As a result BA values obtained using pharmacokinetic and pharmacodynamics parameters may be substantially different.

$$
E=\frac{E_{\max } \times C^{n}}{E C_{50}^{n}+C^{n}}
$$

Emax is the maximal effect attributable to the drug; $\mathrm{EC}_{50}$ is the concentration producing $50 \%$ of the maximum effect and ' $n$ ' is Hill's coefficient [10]. Beside this Pharmacokinetics depends upon the homogenization speed which may leads to $90 \%$ predetermined range (11) ( Figure 1).

\section{Oral, Transdermal, Lipophilic administrations of drugs}

Transdermal is a route of administration wherein active ingredients are delivered across the skin for systemic distribution. Examples include transdermal patches used for medicine delivery, and transdermal implants used for medical or aesthetic purposes [12]. Transdermal route is known to reduce the adverse effects and increased bioavailability of drugs [13]. Drugs are normally taken orally as tablets or capsules. The drug (active substance) itself needs to be soluble in aqueous solution at a controlled rate. Such factors as particle size and crystal form can significantly affect dissolution. Fast dissolution is not always ideal. For example, slow dissolution rates can prolong the duration of action or avoid initial high plasma levels. Treatment of active ingredient by special way as spherical crystallization can have some advantages for drug formulation [9]. Oral ingestion is the most convenient and commonly employed route of drug delivery due to its ease of administration, high patient compliance, cost-effectiveness, least sterility constraints and flexibility in the design of dosage form. Many of the generic drug companies are inclined more to produce bioequivalent oral drug products. The high costs and time involved in new drug development, expiry of patents for a significant number of drug molecules, ease of manufacturing and ready availability of technology for the production of oral drug products are also driving the generic pharmaceutical companies towards the development of bioequivalent oral dosage forms. However, the major challenge with the design of oral dosage forms lies with their poor bioavailability.

The oral bioavailability depends on several factors including aqueous solubility, drug permeability, dissolution rate, first-pass metabolism, pre-systemic metabolism and susceptibility to efflux mechanisms. The most frequent causes of low oral bioavailability is attributed to poor solubility and low permeability. The tremendous pharmaceutical research in understanding the causes of low oral bioavailability has led to the development of novel technologies to address these challenges. One of the technologies is to design a prodrug with the required physicochemical properties to improve the oral bioavailability. For example, the prodrug approach resulted in improved bioavailability of etilevodopa, caepecitabine, oseltamivir, docarpamine and simvastatin. For BCS class IV drugs with poor solubility and poor membrane permeability and BCS class III drugs with high solubility and low permeability, prodrug approach is the best option to enhance their bioavailability. Though prodrug approach is an exciting way of improving the oral bioavailability of BCS class II drugs, it requires extensive studies to establish the safety profile of prodrugs in humans, which ultimately may result in failure. Furthermore, the potential drawback of this approach is the reduced solubility of the prodrug. In today's market, more than $40 \%$ of oral drug products contain poorly soluble drugs, and among the pharmacopoeia, this share is more than $30 \%$. For these BCS class II drugs with low solubility and reasonable permeability, drug dissolution step is the rate-liming process of drug absorption. When administered as oral dosage forms, the pharmaceutical formulation plays a critical role in the absorption of such drugs from gastrointestinal tract.

The main technologies to achieve the enhanced oral bioavailability of drugs with poor aqueous solubility include the use of micronization, nanosizing, crystal engineering, solid dispersions, cyclodextrins, solid lipid nanoparticles and other colloidal drug delivery systems such as microemulsions, self-emulsifying drug delivery systems, selfmicroemulsifying drug delivery systems and liposomes.Microemulsions are novel pharmaceutical formulations are thermodynamically stable, transparent, low viscosity, easy to prepare and isotropic dispersions designed to enhance the oral bioavailability of poorly soluble drugs [14].

There are many varieties of oral drugs which are formulated in different manner whether with lipophillic substance, biodegradable substance or a combination of other drugs. The way of action or delivery is fast as compared to transdermal. Transdermal deals with skin where oral delivery comes directly in contact with the body parts. Few examples of drugs are:

"Atorvastatin" (AT), a synthetic reversible inhibitor of the microsomal enzyme HMG-CoA reductase belongs to the second generation of statins. AT and its metabolites are substrates for CYP3A4, uridine diphospho glucuronosyltransferases (UGT1A1, UGT1A3), P glycoprotein (P-gp), organic anion-transporting polypeptide (OATP-C) and proton-monocarboxylic acid co-transporter (MCT). Losartan (LS) is an orally active, highly selective antagonist that blocks the binding of angiotensin II to the angiotensin II type 1 (AT1) receptor subtype without agonist properties. LS are very effective and safe in the treatment of hypertension. Three subjects were withdrawn from study due to adverse events such as dizziness and vomiting, pain in the left ear. CYP3A4 is also the major enzyme responsible for the conversion of AT to its metabolites. LS or its metabolite are not known to alter the activ- 
ity of CYP3A4.The study demonstrates pharmacokinetically significant but clinically insignificant interaction between AT and LS in healthy subject after administration of single oral doses simultaneously [15].

Formulation of "Piroxicam", mechanism related to prostaglandin synthetase inhibition. Metabolism occurs by hydroxylation at the 5 position of the pyridyl side chain and conjugation of this product; by cyclodehydration; and by a sequence of reactions involving hydrolysis of the amide linkage, decarboxylation, ring contraction and $\mathrm{N}$-demethylation [16].

"Pitavastatin" is a highly effective lipid-lowering drug with a distinctive metabolic pathway that has a low potential for drug interactions. When it enters the body it coagulates into metabolite Pitavastatin lactone which is observed after plasma validation [17]. Pitavastatin lactone is the chief metabolite of the drug.

Phytochemicals or plant extracts mixed with the present antibiotics gives more potential treatment against diseases such as: "Kumazasacytoplasmic extract". The antimicrobial activity (as MIC) of cytoplasmic extract from Kumazasa or each antibiotic (ampicillin: ABPC, vancomycin: VCM, clarithromycin: CAM, or tetracycline: TC) was measured against both Gram-positive and Gram-negative microbes. The Kumazasa-cytoplasmic extract (Kumazasa-CE) displayed a markedly potent antibacterial activity against Gram-positive bacteria such as Staphylococcus aureus, Enterococci and Streptococcus pneumonia [18].

"Cyclobenzaprine hydrochloride" is a centrally acting muscle relaxant. Cyclobenzaprine improves global functioning of patients with fibromyalgia with a modest improvement in sleep quality. The relative bioavailability between Cyclobenzaprine and caffine is analyzed for the excellent pharmacodynamics study [19]. Drug and metabolite plays an important role when combined each other. The rate of bioavailability is same but the measurement range depends upon the test and references used. Two formulations differ in their extent of absorption. Parent drug data are more sensitive to detect differences in the rate of absorption. Example cyclobenzaprine hydrochloride and caffine [20].

"Tetrahydrofuran", "oxymatrine" and "phospholipids" were resolved into the medium, oxymatrine phospholipid complex was formed. After administration of the complex it shows the increase absorption in gastrointestinal tract and pharmacokinetic dynamic studies done [21].

"Pentoxifylline" (PX) (1-[5-oxohexyl]-3, 7-dimethylxantine) is an orally active hemorheological drug for the treatment of intermittent claudication or other circulatory disorders. Chitosan $(\mathrm{CH})$ salts acts as absorption enhancers or biocompatible, biodegradable, natural polymer [22].

"Darbepoetin alfa" (DA) is the hyperglycosylated analog of recombinant human erythropoietin ( $\mathrm{rHuEPO}$ ) that stimulates red blood cell production (erythropoiesis). This is a subcutaneous/ transdermal drug [23].

"Emtricitabine" (FTC; Emtriva), a potent doxycytidine nucleoside reverse transcritase inhibitor is used to treat human immunodeficiency virus (HIV) infection. Emtricitabine is rapidly and extensively absorbed followed oral administration, with peak plasma concentration [24].

"Doxycycline" a member of tetracycline antibiotic group is commonly used to treat chronic prostatitis and syphilis. Doxycycline is a water soluble drug. Hence, an attempt has been made to extract the drug from plasma by precipitating the plasma samples with solvents like acetonitrile, perchloric acid and methanol. It was found that the analyte recovery was less with these precipitating agents, may be due to decrease in the solubility of doxycycline in water after the addition of these solvents [25].

"Fluconazole" is an orally active bistriazole antifungal agent which is used in the treatment of topical and systemic candidiasis and in the treatment of cryptococcal infections in patients with AIDS. Fluconazole has a high degree (90\%) of bioavailability after oral administration, displays $\mathrm{pH}$-independent absorption, and is eliminated, predominantly unchanged, by renal excretion. Fluconazole can be given orally and intravenously and is usually well tolerated [26].

"Amtolmetin guacil" (AG) is a non-acidic prodrug of tolmetin, having similar NSAID properties like tolmetin with additional analgesic, antipyretic and gastroprotective properties. Amtolmetin is formed by amidation of tolmetin by glycine. Amtolmetin guacil is hydrolysed in the gastrointestinal tract and is absorbed predominantly as tolmetinglycinamide (TG). TG is metabolized to tolmetin (T) in the tissues, which is then metabolized to methyl carboxybenzoyl pyrrole acetic acid [27].

"Clopidogrel" is chemically related to ticlopidine. The drug which reduces platelet aggregation is extensively used for prevention of thrombosis in patients undergoing placement of a coronary stent. The drug is rapidly, but incompletely, absorbed after oral administration and extensively metabolized to an active metabolite. The parent drug and active metabolite are low in plasma. The major circulating compound however, is an inactive carboxylic derivative, which its blood concentration is used to document the pharmacokinetic profile of clopidogrel. Clinical studies have showed that Clopidogrel added to aspirin is beneficial in the treatment of patients with acute ST-elevation [28].

"Troxipide" is a novel gastric mucosal protective agent with chemical formula 3, 4, 5-trimethoxy-N-(3-piperidyl) benzamide. Anti-ulcer effect of troxipide is due to increase in gastric mucosal blood flow, mucus secretion, glycoprotein excretion in the gastric mucosa and inhibition of inflammatory responses and mucosal injury mediated by neutrophils [29].

"Ofloxacin" [OFX] is a well known synthetic carboxyquinolone antimicrobial agent with a broad antimicrobial spectrum against gram positive and gram-negative bacteria and is considered safe. The bactericidal action of OFX results from interference with enzyme DNA gyrase that is needed for the synthesis of bacterial DNA. Its favorable pharmacokinetic feature includes good oral absorption and lack of metabolism resulting decrease in drug interaction [30].

"Artesunate" is rapidly absorbed and hydrolysed to its pharmacologically active metabolite, dihydroartemisinin. Conversion of artesunate to dihydroartemisinin occurs chemically within the gastrointestinal tract and is further catalysed by tissue and blood esterases [31].

Combinations of "rifampicin" (R, RMP), "Isoniazid" (H, INH), "pyrazinamide" (Z, PZA) and "Ethambutol" (E, EMB) for the anti-TB drugs are stable under storage conditions. Patients receiving a lower therapeutic dose due to a substandard anti-TB drug could lead to drug resistance and treatment failure despite $100 \%$ adherence to the treatment regimen. The bioavailability of rifampicin from the formulations can also be explained on the basis of physiochemical properties of the drugs and dosage forms. Since rifampicin tablets are film coated, this dosage form presents all the potential problems of compressed tablets that impose a physical barrier between the gastrointestinal fluid and tablet containing the drug [5]. 
"Valsartan", an angiotensin receptor blocker (ARB), is a widely used antihypertensive drug approved world-wide either as monotherapy or in combination with other antihypertensive agents. The pharmacokinetics of valsartan is linear and dose proportional across a wide dose range (80-320 mg). Valsartan is rapidly absorbed after oral administration, reaching peak plasma concentration (Cmax). The oral bioavailability of valsartan is only $23 \%$ and about $95 \%$ is bound to serum proteins mainly albumin [32].

Combination contraceptives like "Ethinylestradiol" are used to prevent pregnancy in women. Ethinylestradiol is rapidly and completely absorbed from the gastrointestinal tract. Ethinylestradiol undergoes extensive first-pass metabolism, and its absolute bioavailability is approximately $40 \%-60 \%$. After single oral administration, peak plasma concentrations of ethinylestradiol are reached and changes. "Gestodene" has been combined with low doses of ethinylestradiol to provide lowdose combination oral contraceptive (COC) preparations. While lowdose COCs are the most widely prescribed form of oral contraceptive and have a low failure rate in terms of unintended pregnancies, approximately $50 \%$ of all women who begin taking oral contraceptives discontinue their use within one year. Gestodene is rapidly and completely absorbed from the GI tract with peak plasma concentration occurring in about 1-2 hours. Gestodene is extensively metabolised in the liver but does not undergo significant first pass metabolism [33].

"Flurbiprofen" is a non-selective cyclo-oxygenase inhibitor and member of a series of alkanoic acid derivatives and has shown to have anti-inflammatory and analgesic activity. Flurbiprofen has also caused a dose dependent inhibition of collagen-induced platelet aggregation in patients with platelet-rich plasma [34].

"Candesartan" cilexetil administered orally, which is completely converted during enteric absorption to the active compound, candesartan. Candesartan cilexetil is rapidly and completely hydrolysed to the active compound candesartan during absorption from the gastrointestinal tract. Candesartan is a potent, long-acting, selective angiotensin II AT, receptor blocker which is well-tolerated and effective with a once-daily dosing regimen in hypertensive patients. "Felodipine" is a calcium antagonist, within the dihydropyridine group, which lowers blood pressure by a selective action on the vascular smooth muscle in the resistance vessels. This benefit is abolished by the poor bioavailability of the drug, which-although being almost completely absorbed from the gastrointestinal tract-is only $15 \%$ bioavailable after oral administration. The poor oral bioavailability of felodipine was attributable to its extensive first-pass metabolism and the very low water solubility of the drug [35].

"Metformin hydrochloride" (N, N-Dimethyl-imido-di-carbonimidic diamide hydrochloride) is an oral antihyperglycaemic agent that improves glucose control in patients with type 2 diabetes by lowering both basal and postprandial plasma glucose level. Metformin $\mathrm{HCl}$ decreases hepatic glucose production, decreases intestinal absorption of glucose, and improves insulin sensitivity by increasing peripheral glucose uptake and utilization [36].

"Nevirapine" (NVP) is a non-nucleoside reverse transcriptase inhibitor (NNRTI) that binds to the membrane of the HIV virus inhibiting viral replication. It also probably inactivates cell free virions present in the genital tract and in human milk. Nevirapine is well absorbed by mouth, widely distributed, penetrates the cells very well because it is lipophilic, rapidly transferred across the placenta. A substantial quantity of drug appears in breast milk [37].
"Pancrelipase" (PancrecarbR) evaluation of drug absorption following administration in different regions of the gastrointestinal tract; measurement of the effect of pancreaticobiliary secretions and gastrointestinal transit time on drug absorption and pharmacokinetics [38].

"Simvastatin" lowers plasma cholesterol by inhibiting 3-hydroxy3-methylglutaryl-CoA reductase. It is widely used in the treatment of hypercholesterolemia. Plasma levels of simvastatin following therapeutic oral doses are reported to be very low. Therefore, to monitor the low therapeutic drug level, it is urgent to develop sensitive and selective methods [39].

"Ciprofloxacin" is a quinoline carboxylic acid derivative with broad antibacterial activity against both gram-positive and gram-negative bacteria. Chemically it is 1-cyclopropyl-6-fluoro-1, 4-dihydro-4-oxo7-(1-piperazinyl)-3-quinolinecarboxylic acid]. It was found to be more active against enterobacteriaceae than the older drugs of this class, such as nalidixic acid, with minimum inhibitory concentrations Ciprofloxacin XR and ciprofloxacin immediate-release tablets are not interchangeable. Once-daily ciprofloxacin XR is safe, effective, and no inferior to twice-daily ciprofloxacin immediate-release (IR) in the treatment of acute infection. But taking ciprofloxacin to prevent disease is a better method which helps not to increase the infection further [40].

"Nitazoxanide" (2-(acetolyoxy)-N-(5-nitro-2-thiazolyl) benzamide) is an oral broad-spectrum parasiticidal agent. In Mexico, the oral powder for suspension of nitazoxanide is indicated for the treatment of antiprotozoal (Entamoeba histolytica, Giardia lamblia and Cryptosporidium parvum) and anthelmintic (Ascaris lumbricoides, Taenia solium, Taenia sagignata; Trichuris trichuria Hymenoleptis nana and Fasciola hepatica) infections in patients aged one year or older. Nitazoxanide is a prodrug which is rapidly metabolized (half-life of about 6 minutes in plasma) to its major active metabolites tizoxanide and tizoxanide glucuronide. oral administration of nitazoxanide (tablets or oral suspension), maximum plasma concentrations of the active metabolites (tizoxanide and tizoxanide glucuronide) are observed within 1 to 4 hours [41].

"Pravastatin sodium" is an anti-hypercholesterolemic agent having an inhibitory activity against 3-hydroxy-3- methylglutaryl coenzyme A (HMG-CoA) reductase, the rate-determining enzyme in the cholesterol synthesis and conversion of HMG-CoA to mevalonate. Pravastatin is characterized as one of the best, due to the hydroxyl group attached to its decalin ring, which results in a greater hydrophilicity than other HMG-CoA reductase inhibitors. Many pharmacokinetic studies have been performed and different HMGCoA reductase inhibitors have been compared [42].

Oral administration, of both "trimetazidine" tablets is rapidly absorbed. The immediate-release of tablet shows the reached peak plasma concentration within 2 hours compared to 5 hours for the modified release. Trimetazidine is widely distributed throughout the body [43].

"Citicoline" (CDP-choline or cytidine 51- diphosphocholine) is both an endogenous intermediate in the biosynthesis of phosphatidylcholine (PC) which may act as a neuroprotector in several models of neurodegeneration and use as a therapeutic agent to treat stroke and brain injury, or in combined with levodopa, to treat Parkinson's disease. But in human, cytidine undergoes rapid catabolism by cytidine deaminase $(\mathrm{CD})$. The deaminated product uridine, which is the central intermediate and also named as the precursor of UTP (Uridine tri phosphate), CTP (cytidine tri phosphate), and CDP-choline, increased proportionally to the doses orally administered, and then was used as 
metabolite of CDP-choline to evaluate the characteristics of the pharmacokinetics and bioequivalence of CDP-choline oral preparations [44].

"Fenoterol" is a B2 adrenergic agonist, which is effective bronchodilator in animals and human when given by inhalation or by oral route. Following the administration of several B2 stimulants oral or inhaled, fenoterol is superior to isoprenaline, orciprenaline and salbutamol in protecting against bronchospasm and is longer acting. Fenoterol is rapidly absorbed following oral ingestion or inhalation. Its oral bioavailability is low, only $2 \%$. It is rapidly metabolized to sulphate and glucuronide conjugates.Therefore, the development of transdermal controlled drug delivery system of fenoterol without adverse effects which could occur when administered orally is very important [45].

"Quetiapine" is rapidly absorbed in the gastrointestinal tract, and its absorption is unaffected by food [46]. Quetiapine is indicated for the treatment of schizophrenia and bipolar disorder. Quetiapine is metabolized by the liver [3].

"Cefdinir" is one of the third generation cephalosporins which have broad spectrum antibacterial activity. Cefdinir dispersible tablet disintegrates very fast and disperses homogenously, it is easily to be absorbed and highly effective [47].

Minocycline is more lipid soluble than doxycycline and the other tetracyclines and widely distributed in body tissues and fluids, but the penetration into the CSF (Cerebrospinal Fluid) is relatively poor. It crosses the placenta and is distributed into breast milk [2].

"Acyclovir" is a synthetic purine nucleoside analogue with in vitro and in vivo inhibitory activity against herpes simplex virus types 1 (HSV-1), 2 (HSV-2), and varicella-zoster virus (VZV). Absorption of acyclovir from the gastrointestinal tract is variable and incomplete; $10 \%-30 \%$ of an oral dose may be absorbed. This poor systemic bioavailability is considered to be a result of the characteristics of the drug itself and not its delivery vehicle. Because of its high hydrophilic nature, absorption of acyclovir occurs mainly by passive diffusion mechanism and it is slow, variable and incomplete manner. Therefore, acyclovir is replaced with its prodrug valacyclovir, the L-valyl ester of acyclovir has been used orally to increase the systemic bioavailability. Acyclovir is well tolerated whether administrated by ocular, topical, oral or intravenous routes [48].

"Esomeprazole" is absorbed rapidly after oral administration. Esomeprazole is metabolized extensively in the liver by two cytochrome P450 isoenzymes to metabolites devoid of antisecretory activity. The drug is primarily metabolized by CYP2C19 to hydroxyl and desmethyl metabolites and to a lesser degree by CYP3A4 to sulfone metabolites [49].

"Omalizumab" (XOLAIR ${ }^{\circledR}$ is a recombinant DNA-derived humanized IgG monoclonal antibody that selectively binds to human IgE. Omalizumab has been approved as an add-on therapy in adults, adolescents and children ( $\geq 6$ years) for the treatment of IgE-mediated severe allergic asthma in the EU, and in adults and adolescents ( $\geq 12$ years) with moderate-to-severe allergic asthma in the U.S. Omalizumab was first launched as a sterile, white, preservative free, lyophilized powder in a single-use vial that has to be reconstituted with sterile water for injection. The solution should be administered immediately after reconstitution. Omalizumab exerts its pharmacological effect by binding to circulating IgE, whatever its allergen specificity, and prevents subsequent IgE-mediated responses [50].
The mean absolute bioavailability of orally administered "desvenlafaxine" in humans is $80 \%$; the concentrations of (R)- and (S)-desvenlafaxine enantiomers in all plasma samples assayed were approximately equal, and demonstrated similar pharmacokinetic parameters [51].

"Imatinib mesylate" is the first and only effective drug for the treatment of gastrointestinal stromal tumour (GIST) at present. The constitutive activation of KIT receptor tyrosine kinase is critical in the pathogenesis of GISTs. Imatinib is rapidly absorbed after oral administration with a peak plasma concentration occurring at 2-4 hours. Additionally, Imatinib absorption is not significantly affected by food [52].

"Paracetamol" is well absorbed from the gastrointestinal tract and it relatively poorly binds to blood proteins $(20 \%-50 \%)$. A part of the ingested drug dose is coupled in liver with glucuronic acid (60\%), active sulfonic acid or glycine, and excreted with urine in the form of such compounds. Accumulation of this metabolite can lead to liver necrosis for a long-term [53].

"Gabapentin" can be actively transported across the brain-blood barrier and the gut via the L-system amino acid transporter, which recognizes L-isoleucine, L-leucine, Lphenylalanine and L-valine. Gabapentin has some lipophilicity and readily crosses the blood-brain barrier. Its volume of distribution is large, estimated as 50 to $60 \mathrm{~L}$ in healthy volunteers. The drug is not bound to human plasma proteins [7].

"Capecitabine" is administrated orally, morning and evening. Capecitabine is an adjuvant treatment for colon cancer and for the treatment of metastatic breast cancer in particular patients whose pathology did not improve during treatment with other therapeutic agents [54].

"Rapamycin" released from ReGel exhibited antiproliferative activity similar to the free Drug. ReGel is thermosensitive which allows for easy mixing with rapamycin and also easy injection into the physiologic site of interest. Basically drug is used after grafting of the body parts which is applied transdermally [55].

"Aceclofenac", a nonsteroidal anti-inflammatory drug (NSAID) has been recommended orally for the treatment of various kinds of pain, inflammation, rheumatoid arthritis and osteoarthritis oral administration of aceclofenac causes gastrointestinal (GI) ulcers and GI bleeding Transdermal route is known to reduce these adverse effects and increased bioavailability of drugs [13]. Nanoemulsion or nanocarriers improve solubility and dissolution of the lipophilic drug aceclofenac [56].

"Vedolizumab" is a gut-selective biologic that has shown efficacy in ulcerative colitis (UC) and Crohn's disease (CD). Vedolizumab demonstrates dose-proportional pharmacokinetics and maximally saturated $\alpha(4) \beta(7)$ receptors over the tested dose range. Vedolizumab treatment reduced fecal calprotectin levels compared with placebo process [57].

"Xanthohumol" (XN), a dietary flavonoid found in hops, may have health-protective actions against cardiovascular disease and type 2 diabetes. The pharmacokinetic approach shows intravenous and injection or oral intake of low ,high dose is applicable. But the approach is applicable for oral intake [58].

"Dasatinib" a cancer drug orally ingested. The drug interaction between the dasatinib and gastric acid suppressants shows the pharmacokinetic analysis details of the drug act. Administration of an acid suppressant such as famotidine, nizatidine, and lansoprazole can decrease the absorption of dasatinib from the gastrointestinal tract, thereby resulting in a significant decrease in the plasma concentration of da- 
satinib. The combination of dasatinib and an acid suppressant requires careful therapeutic drug monitoring of the dasatinib plasma concentration to ensure effective patient exposure to the drug [59].

Docosahexaenoic acid (DHA) and DHA-containing ethanolamine plasmalogens (PlsEtn) are decreased in the brain, liver and the circulation in Alzheimer's disease(AD). Peroxisomal deficits is a process that probably starts early in the AD. An ether lipid precursor of plasmalogens is orally bioavailable augmenting the circulating levels of unesterified DHA and DHA-containing PlsEtn and PtdEtn. Phosphatidylethanolamines were generated via de-alkylation/re-acylation reactions [60].

Sagopilone identifies and preferentially used for the treatment of taxane-resistant cancer. Sagopilone intravenous infusion leads to doselimiting toxicity (DLT) which shows peripheral sensory neuropathy. Pharmacokinetic data for sagopilone gives no accumulation after repeated administration which will help define the treatment of advanced tumors in more extensive clinical trials [61].

Dalfampridine is a novel drug with a unique mechanism for the symptomatic management of multiple sclerosis (MS). Dalfampridine blocks potassium channels on demyelinated neurons and allows normal electrical conduction, thus improving locomotor difficulty. Dalfampridine is rapidly absorbed after oral administration, reaching its peak plasma concentration. Dalfampridine is not an inhibitor or inducer of a major cytochrome P-450 isoenzyme. Dalfampridine side effects are insomnia, dizziness, headache, nausea, and weakness [62].

\section{Pharmacokinetics \& dynamic analysis}

The plasma concentration obtained from metabolites was fed with computer software BASICA ${ }^{\oplus}$, WinNonlin software etc. This determines the pharmacokinetics parameters. The maximum metabolites (i.e. T \& TG) concentrations (Cmax) and the corresponding peak time (Tmax) were determined by checking the individual drug plasma concentration- time profiles $[27,30]$. Immediately after the administration of the drug through pharmacokinetic parameters it straight away followed with validation and formulation depending upon the concentration and time. Pharmacokinetic, pharmacodynamics modeling has demonstrated that with this split dose treatment regimen. Area under the plasma concentration time curve from time zero to the last quantifiable concentration (AUClast) was calculated.

The maximum observed concentration (Cmax) and the time of the maximum observed concentration (Tmax) were taken directly from the data without interpolation. After the administration the drug undergoes LC-MS analysis relevant NMR fractions containing drug related material were analyzed qualitatively to assist metabolite identification $[63,31]$. Pharmacokinetic approach used for the BE assessment of systemically absorbed drugs is not considered appropriate to study the bioavailability (BA) and/or BE of topically applied drugs other than dosage forms such as transdermal patches and other products intended for local application which contain drugs intended for the systemic circulation [64]. Pharmacodynamics assessment is done through the radio immunoassay [32]. The estimitated geometric mean ratios of AUC and Cmax is done respectively. The inter subject variability of pharmacokinetics parameter should be of a range between $20 \%-60 \%$. Considering the high variability, the $90 \%$ confidence intervals of AUC and Cmax were well within range. The AUC and Cmax data for the two formulations were analyzed by ANOVA to determine the graph and results $[54,32]$. Pharmacodynamic parameter analyzed was area under the curve $\left(\mathrm{AUC}_{0-\mathrm{t}}\right)$ from 0 to time $\mathrm{t}$ (time of the last measured drug effect - $120 \mathrm{sec}$ ), calculated by trapezoidal method. The analyses were carried out by fitting a doubly repeated measurement (period and times within periods) model. As suggested by residual analysis, log-natural transformation was used for response variable. To verify the equivalence between the formulations, $\log$ transformed $\mathrm{AUC}_{0-\mathrm{t}}$ was used as the response and a linear mixed model was fitted. The fixed effects were

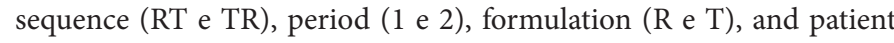
within sequence was the random effect [8].

It is important to select a dose in the range of the linear responses when pharmacodynamics parameters are used for BA and BE determination [11]. The pharmacokinetics analysis was Individual plasma concentration-time curves were constructed; Cmax and Tmax were directly obtained from the curve. AUC from time 0 (baseline) to 24 hours $\left(\mathrm{AUC}_{0-24}\right)$ was calculated using the trapezoidal rule. From the terminal log-decay phase, elimination rate constant (ke) was estimated using linear regression, and $t_{1 / 2}$ was estimated using the following equation:

$\mathrm{t}_{1 / 2}=\ln 2 / \mathrm{ke}$

Where $\ln$ was defined as the natural log;

And extrapolation of AUC from baseline to infinity $\left(\mathrm{AUC}_{0-\infty}\right)$ was calculated as follows:

$$
\mathrm{AUC}_{0-\infty}=\mathrm{AUC}_{0-24}+\left(\mathrm{C}_{24} / \mathrm{ke}\right)
$$

Where $\mathrm{C}_{24}$ was defined as concentration at 24 hours [65].

The two formulation analysis can also be done by the database searches. Some drugs whose formulations are different in such case the database searches helps in analyze the bioequivalence rate and approaches. The AUC value determines the possibility of reaction. The variability depends on the concentration of the drug and the overall bioavailability which may vary [66]. Drug interaction leads to different reaction, similarly in hepatic allograft the drug pharmacokinetic analysis shows orally ingested drug has highly predictive AUC. The concentration of the drug, efficacy and adverse reaction along with the time normalization is important in predicting the data [67].

\section{Sample analysis}

The blood samples are the most useful sample for drug metabolism test and qualification test. The urine samples are also the good collected sample for drug test. Plasma concentrations determined through the method validated by liquid chromatography-mass spectrometry (LC-MS/MS), HPLC. The mass spectrometer was equipped with negative electrospray source (ESI) by using multiple reactions monitoring (MRM) mode.

Pharmacokinetics/pharmacodynamics and statistical analysis is carried out by using the software GraphPad Prism ${ }^{\circledR}$ version 4.0, WinNolin $^{\circledR}$ version 5.0.1, EquivTest ${ }^{\oplus}$ version 2 and Microsoft Excel ${ }^{\oplus}$.The bioanalytical method was validated for specificity, selectivity, linearity, precision, accuracy, recovery of extraction and stability according to the US FDA guidance. Liquid chromatography tandem mass spectrometry was also used to determine plasma drug concentrations $[42,68]$. The overall sampling time is long enough to describe the pharmacokinetic profile of investigated drugs after oral administration of formulations [68]. Drug administration involves homogenization speed which effects the drug pharmacokinetics when used as a suspension formulation [11]. Pharmacokinetic and pharmacodynamic analysis for some erythromycin or intravenous sample of plasma can also be done through ELISA [69]. 


\begin{tabular}{|c|c|c|c|}
\hline Serial no: & $\begin{array}{l}\text { Name of the } \\
\text { Drugs }\end{array}$ & Mode of Absorption & Side Effects of the drugs \\
\hline 1 & Aceclofenac & Oral, transdermal & Diarrhea, nausea, indigestion, abdominal pain, dizziness and rash \\
\hline 2 & Atorvastatin & Oral & $\begin{array}{l}\text { Nose inflammation, joint pain, diarrhea, pain in extremity, urinary tract infection, indigestion, nausea, } \\
\text { muscle and bone pain, muscle spasms, sleeplessness }\end{array}$ \\
\hline 3 & Losartan & Oral & $\begin{array}{l}\text { Swelling, abdominal pain, chest pain, nausea, headache, inflammation of pharynx, diarrhea, indigestion, } \\
\text { muscle pain, sleeplessness, cough and sinus disorder. }\end{array}$ \\
\hline 4 & Naproxen Sodium & Oral & $\begin{array}{l}\text { Nausea, constipation, diarrhea, indigestion and mouth ulcer, convulsions. Skin- Itching, skin eruptions, } \\
\text { increased sweating and bruising. Liver-Jaundice and abnormal liver function tests [74]. }\end{array}$ \\
\hline 5 & Rapamycin & Oral ,intravenous & Thrombocytopenia and hyperlipidaemia \\
\hline 6 & Piroxicam & Oral & $\begin{array}{l}\text { Heartburn, nausea, ulcers } \\
\text { Blood - Anemia and increased bleeding time. Central Nervous System - Dizziness and headache. Skin - } \\
\text { Itching and rash. ENT - Ringing in the ear. Genitourinary - Abnormal kidney function. }\end{array}$ \\
\hline 7 & Cyclobenzaprine & Oral & $\begin{array}{l}\text { Drowsiness, headache, dizziness, blurred vision, nausea, abnormal taste, palpitations, tremor, dry throat, } \\
\text { pimples, attention disturbances, sleeplessness, fatigue, constipation and indigestion. }\end{array}$ \\
\hline 8 & Pentoxifylline & Oral & $\begin{array}{l}\text { Heart - Chest pain, abnormal heart rhythm, palpitations and flushing. } \\
\text { Gastrointestinal - Abdominal discomfort, Central Nervous System - Agitation, nervousness, dizziness, } \\
\text { drowsiness, headache, sleeplessness, tremor and blurred vision. }\end{array}$ \\
\hline 9 & Darbepoetin Alfa & Intravenous, Sub-Cutaneous & $\begin{array}{l}\text { Local - Injection site pain. } \\
\text { Body As A Whole - Swelling in the extremities, fatigue, fever, death, fluid retention, influenza-like } \\
\text { symptoms, and weakness and bleeding. }\end{array}$ \\
\hline 11 & Ofloxacin & Oral, Eye Drops, & $\begin{array}{l}\text { Nausea, headache, sleeplessness, genital itching in women, dizziness, vaginal inflammation, diarrhea } \\
\text { and vomiting. }\end{array}$ \\
\hline 10 & Emtricitabine & Oral & Headache, diarrhea, nausea, fatigue, pains, weakness, increased cough, and nose inflammation. \\
\hline 12 & Artesunate & $\begin{array}{l}\text { Oral, Intravenous, } \\
\text { Intramuscular }\end{array}$ & Temporary and reversible anemia, slow heart rate, rash and fever. \\
\hline 13 & Mefloquine & Oral & $\begin{array}{l}\text { Dizziness, muscle pain, nausea, fever, headache, vomiting, chills, diarrhea, skin rash, abdominal pain, } \\
\text { fatigue, loss of appetite and ringing in the ear. }\end{array}$ \\
\hline 14 & Doxycycline & Oral & $\begin{array}{l}\text { Inflammation and difficulty in swallowing. Skin-Rash and Blood Urea Nitrogen. Hypersensitivity-Hives, } \\
\text { swelling, shock and redness of the skin. }\end{array}$ \\
\hline 15 & Erythromycin & Oral & Nausea, vomiting, abdominal pain, diarrhea and loss of appetite. \\
\hline 16 & Azithromycin & Oral & $\begin{array}{l}\text { Skin- Itching, severe allergic reactions and smell sensation. Respiratory- Increased cough, inflammation } \\
\text { of pharynx, pleural effusion and rhinitis. }\end{array}$ \\
\hline 17 & Melatonin & Oral & Drowsiness, change in sleep pattern and headache \\
\hline 18 & Desvenlafaxine & Oral & $\begin{array}{l}\text { Nausea, dizziness, sleeplessness, excessive sweating, constipation, drowsiness, decreased appetite, } \\
\text { anxiety and specific male sexual function disorders. }\end{array}$ \\
\hline 19 & Imatinib Mesylate & Oral & $\begin{array}{l}\text { Heart-Compression of the heart, skin, redness of the skin and flushing. Eye and ENT- Eye edema, } \\
\text { inflammation of conjunctiva, dry eye }\end{array}$ \\
\hline 20 & Digoxin & Oral & Toxicity levels should be monitored in patients to avoid renal toxicity \\
\hline
\end{tabular}

Table 1: The following table contains the name of the drugs, its mode of absorption and the side effects after being fully absorbed by the body [75].

\section{Discussion}

Overall idea of route of administration of drug is being observed. The oral administration overcomes the mode of transmission of drug through transdermal procedure. Few poorly soluble drugs can be incorporated in the oil phase to enhance their oral bioavailability. One of the challenges in formulating microemulsions, SEDDS or SMEDDS (isotropic solutions of oil) is the limited availability of formulation components. The excellent research reports enhanced oral bioavailability of poorly soluble drugs [14]. The biotechnologically modified administrations of Calcium in body through natural source like carrot, phytochemicals from spices, are the different source of administration to the body [70,71]. Drug verification through pharmacokinetics method leads to validity analysis and different differentiation methods for the perfect pharmacodynamics methodology. Bioequivalence shown in all pair-wise comparisons with the $90 \%$ confidence intervals of the AUC ratios falling within the standard bioequivalence limits of $80 \%-125 \%$. A similar pharmacokinetic and pharmacodynamics profile of drugs shows it's well tolerated and safety upon administration of studies [72]. Solubility has a crucial role in the success of a drug candidate. Compounds with low solubility not only cause problems for in vitro and in vivo assays, but also add significant burdens to drug development. Drug discovery and drug development often have different solubility screening requirements and methodologies have been developed to meet the needs of these different stages [73]. Side effects of the drugs are followed by the Table 1 .

\section{Conclusion}

Novel strategy of a drug is to increase the affinity and protection to health. Drug administration can be done through different strategies which are pharmacokinetically accepted. The pharmacokinetic interaction involves the modification of drug towards its affinity where pharmacodynamics interaction is done with inhibition and enhancement. Whether the drug is orally absorbed or transdermally there effects are different and protect the body. Beside this drug brings the side effects unusually which enhance and helps to produce the better formulated drug which will be kinetically and dynamic way a useful one.

\section{References}

1. David JG, Lisa LVM, Jerold SH, Richard IS (2002) Pharmacokinetics, Pharmacodynamics and Drug disposition. Neuropsychopharmacology: the fifth generation of progress. Lippincott Williams \& Wilkins Philadelphia, USA: 502 524.

2. Setiawati E, Yunaidi DA, Handayani LR, Kurniawan YTI, Simanjuntak R, et al. (2011) Bioequivalence Study of Two Minocycline Capsule Formulations in 
Citation: Parthasarathi D, Gajendra C, Dattatreya A, Sree Venkatesh Y (2011) Analysis of Pharmacokinetic \& Pharmacodynamic Models in Oral and Transdermal Dosage Forms. J Bioequiv Availab 3: 268-276. doi:10.4172/jbb.1000098

Healthy Subjects. J Bioequiv Availab 3: 118-121.

3. Junior EA, Duarte LF, Suenaga EM, de Carvalho Cruz A, Nakaie CR (2011) Comparative Bioavailability of Two Quetiapine Formulations in Healthy Volunteers after a Single Dose Administration. J Bioequiv Availab 3: 178-181.

4. Huixiao H, George P, Fritz S, Srinubabu G, Sudhakar A (2009) Journal of Bioequivalence \& Bioavailability. J Bioequiv Availb 1: 1-2.

5. Hussain S, Malik F, Mehmood W, Hameed A, Riaz H, et al. (2010) Assessment of Bioavailability of Rifampicin as a Component of Anti-tubercular Fixed Dose Combination Drugs Marketed in Pakistan. J Bioequiv Availab 2: 067- 071.

6. Mertens R (2011) Pain therapy in pediatric oncology - Pain experience, drugs and pharmacokinetics. Anasthesiol Intensivmed Notfallmed Schmerzther 46: 736-742.

7. Junior EA, Duarte LF, Pereira R, Pozzebon JM, Tosetti D, et al. (2011) Gabapentin Bioequivalence Study: Quantification by Liquid Chromatography Coupled to Mass Spectrometry. J Bioequiv Availab 3: 187-190.

8. Zollner R, Junior EA, Duarte LF, Perroud MW, Amarante AR (2011) Bioequivalency Study for Inhaled Drugs: A Pharmacodynamic Approach. J Bioequiv Availab S1-004.

9. http://en.wikipedia.org/wiki/Pharmacodynamics.

10. Critchley DJ, Aluri J, Boyd P, Whayman M, Narurkar M, et al. (2011) Bioavailability of three rufinamide oral suspensions compared with the marketed 400-mg tablet formulation: results from a randomized-sequence, open-label, four-period, four-sequence crossover study in healthy subjects. Clin Ther. 33: 146-157.

11. Shakeel F, Mohammed SF, Shafiq S (2009) Comparative Pharmacokinetic Profile of Aceclofenac from Oral and Transdermal Application. J Bioequiv Availab 1: 13-17.

12. Krishnaiah YSR (2010) Pharmaceutical Technologies for Enhancing Oral Bioavailability of Poorly Soluble Drugs. J Bioequiv Availab 2: 28-36.

13. Ahmed T, Kollipara S, Gautam A, Gigras R, Kothari M et al. (2009) Bioavailability and Interaction Potential of Atorvastatin and Losartan on Co-administration in Healthy Human Subjects. J Bioequiv Availab 1: 18-27.

14. Warrington S, Nagakawa S, Hounslow N (2011) Comparison of the pharmacokinetics of pitavastatin by formulation and ethnic group: an openlabel, single-dose, two-way crossover pharmacokinetic study in healthy Caucasian and Japanese men. Clin Drug Investig 31: 735-743.

15. Shirotake S, Nakamura J, Kaneko A, Anabuki E, Shimizu N (2009) Screening Bactericidal Action of Cytoplasm Extract from Kumazasa Bamboo (Sasa veitchii) Leaf against Antibiotics-Resistant Pathogens such as MRSA and VRE Strains. J Bioequiv Availab 1: 80-85.

16. Karalis V, Macheras $P$ (2010) Examining the role of metabolites in bioequivalence assessment. J Pharm Pharm Sci. 13: 198-217.

17. Yue PF, Yuan HL, Yang M, Zhu WF (2009) Preparation, Characterization and Pharmacokinetics in Vivo of Oxymatrine-Phospholipid Complex. J Bioequiv Availab 1: 99-102

18. Teksin ZS, Agabeyoglu I, Yamac K (2009) Bioavailability of PentoxifyllineChitosan Oral Matrix Tablet in Healthy Subjects. J Bioequiv Availab 1: 115-120.

19. Tayama T, Kawakami K, Takama H, Nakashima D, Tanaka H, et al. (2010) The Influence of Formula Concentration on the Absorption of Darbepoetin Alfa after Subcutaneous Administration. J Bioequiv Availab 2: 1-5.

20. Bapuji AT, Nagesh M, Ramaraju D, Syedba S, Kiran R, et al. (2010) A Bioequivalence Study Comparing Two Formulation of Emtricitabine Capsules. J Bioequiv Availab 2: 11-14

21. Selvadurai M, Meyyanathan SN, Rajan S, Padmanaban G, Suresh B (2010) Determination of Doxycycline in Human Plasma by Liquid ChromatographyMass Spectrometry after Liquid-Liquid Extraction and its Application in Human Pharmacokinetics Studies. J Bioequiv Availab 2: 93-97.

22. Palma Aguirre JA, Mireya LG, de Jesus CST, Hernández GR, Mejía-Callejas $J$, et al. (2010) Bioavailability of Two Oral Tablet Formulations of citalopram 20 mg: Single-Dose, Open-Label, Randomized, Two-Period Crossover Comparison in Healthy Mexican Adult Subjects. J Bioequiv Availab 2: 23-27.

23. Loya P, Saraf MN (2010) Determination of Amtolmetin and Its Active Metabolites in Plasma by HPLC-UV: Application to a Bioequivalence Study. J Bioequiv Availab 2: 37-44.
24. Abib E, Duarte LF, Vanunci MLP, Oliveira de DA, Antonelli S, et al. (2010) Comparative Biological Availability of Clopidogrel Formulation in Healthy Volunteers After a Single Dose Administration. J Bioequiv Availab 2: 45-49.

25. Dewan B, Sahu N (2010) Bioequivalence Study of Troxipide Tablet Formulations. J Bioequiv Availab 2: 50-54.

26. Shakya R, Hada M, Thapa P, Saha RN (2010) Comparative Bioavailability of Two Brands of Ofl oxacin in Healthy Human Volunteers. J Bioequiv Availab 2 $55-58$

27. Olliaro P, Ramanathan S, Vaillant M, Reuter SE, Evans, et al. (2010) Pharmacokinetics and Comparative Bioavailability of Artesunate and Mef oquine Administered Separately or as a Fixed Combination Product to Healthy Volunteers and Patients with Uncomplicated Plasmodium falciparum Malaria. $J$ Bioequiv Availab 2: 59-66.

28. Sunkara G, Yeh C, Ligueros-Saylan M, Kawashita H, Koseki N, et al. (2010) Assessment of Ethnic Differences in the Pharmacokinetics and Pharmacodynamics of Valsartan. J Bioequiv Availab 2: 120-124.

29. Junior EA, Duarte LF, Pirasol Vanunci ML, Teixeira ML (2010) Bioequivalence of Two Oral Contraceptive Drugs Containing Ethinylestradiol and Gestodene in Healthy Female Volunteers. J Bioequiv Availab 2: 125-130.

30. Khattak S, Malik F, Hameed A, Ahmad S, Rizwan M, et al. (2010) Comparative Bioavailability Assessment of Newly Developed Flurbiprofen Matrix Tablets and Froben SR® Tablets in Healthy Pakistani Volunteers. J Bioequiv Availab 2: $139-144$.

31. Abib Jr E, Duarte LF, Oliveira L, Barros FP (2011) Evaluation of the Pharmacokinetic Interaction between Candesartan Cilexetil and Felodipine. $J$ Bioequiv Availab 3: 5-10

32. Harahap Y, Purnasari S, Hayun H, Dianpratami K, Wulandari M, et al. (2011) Bioequivalence Study of Metformin $\mathrm{HCl}$ XR Caplet Formulations in Healthy Indonesian Volunteers. J Bioequiv Availab 3: 16-19.

33. Ghosh C, Gaur S, Singh A, Shinde CP, Chakraborty BS (2011) Estimation of Nevirapine from Human Plasma by LC-ESI-MS/MS: a Pharmacokinetic Application. J Bioequiv Availab 3: 20-25.

34. Rizwan AN, Criste R, Nebot N, Wolf KK, Brouwer KLR, et al. (2011) Use of a Muti-lumen Catheter to Assess the Bioavailability of an Enteric-Coated High-Buffered Pancrelipase Formulation in Patients with Exocrine Pancreatic Insufficiency. J Bioequiv Availab 3: 26-31.

35. Ding MJ, Yuan LH, Li Y, Wang S, Wu XL, et al. (2011) Pharmacokinetics and Bioequivalence Study of Simvastatin Orally Disintegrating Tablets in Chinese Healthy Volunteers by LC-ESI-MS/MS. J Bioequiv Availab 3: 32-37.

36. Omari DM, Johary D, Salem II, Najib N, Sallam AA (2011) Bioequivalence of Two Oral Extended Release Formulations of Ciprofloxacin Tablets in HealthyMale Volunteers under Fed and Fasting Conditions. J Bioequiv Availab 3: $38-42$.

37. Balderas Acata JI, Ríos-Rogríguez Bueno EP, Pérez Becerril F, Espinosa Martínez C, Burke-Fraga V, et al. (2011) Bioavailability of Two OralSuspension Formulations of a Single Dose of Nitazoxanide 500 mg: An OpenLabel, Randomized-Sequence, Two-Period Crossover, Comparison in Healthy Fasted Mexican Adult Volunteers. J Bioequiv Availab 3: 43-47.

38. Sampath K, Ramesh N, Kumar S, Sasijith SL, Terish JD (2011) Method Development and Validation of Pravastatin Sodium in Human Plasma by Using LCMS/MS. J Bioequiv Availab 3: 48-51.

39. Chandranipapongse W, Chatsiricharoenkul S, Ruangnapa T, Ngokpol S Sathirakul K, et al. (2011) Bioequivalence Study of Two Formulations of 35mg Trimetazidine Modified Release Tablets in Healthy Thai Volunteers Under Fasting and Fed Conditions. J Bioequiv Availab 3: 52-55

40. Chen K, Liu X, Wei C, Yuan G, Zhang R, et al. (2011) Determination of Uridine in Human Plasma by HPLC and its Application in Citicoline Sodium Pharmacokinetics and Bioequivalence Studies. J Bioequiv Availab 3: 72-76.

41. Elshafeey AH, Hamza YE, Amin SY, Akhlaghi F, Zia H (2011) Enhanced Bioavailability of Fenoterol Transdermal Systems in Rabbits. J Bioequiv Availab 3: 97-100

42. Mahatthanatrakul W, Pradabsang $C$, Sriwiriyajan S, Ridtitid W, Wongnawa (2011) Bioequivalence of a Generic Quetiapine (Ketipinor ${ }^{\circledR}$ ) in Healthy Male Volunteers. J Bioequiv Availab 3: 108-113.

43. Zhang CL, Jiao JJ, Wu YN, Song JQ, Gao WZ, et al. (2011) Study on 
Citation: Parthasarathi D, Gajendra C, Dattatreya A, Sree Venkatesh Y (2011) Analysis of Pharmacokinetic \& Pharmacodynamic Models in Oral and Transdermal Dosage Forms. J Bioequiv Availab 3: 268-276. doi:10.4172/jbb.1000098

Pharmacokinetics and Bioequivalence of Cefdinir Dispersible Tablet in Healthy Chinese Volunteers. J Bioequiv Availab 3: 114-117.

44. Susantakumar P, Gaur A, Sharma P (2011) Comparative Pharmacokinetics, Safety and Tolerability Evaluation of Acyclovir IR $800 \mathrm{Mg}$ Tablet in Healthy Indian Adult Volunteers Under Fasting and Non-fasting Conditions. J Bioequiv Availab 3: 128-138.

45. Islam MS, Akter N, Shohag H, Ullah A, Al Maruf A, et al. (2011) Bioequivalence Evaluation of Two Esomeprazole $20 \mathrm{mg}$ Capsule Formulations in Healthy Male Bangladeshi Volunteers. J Bioequiv Availab 3: 139-143.

46. Rivière GJ, Yeh CM, Reynolds CV, Brookman L, Kaiser G (2011) Bioequivalence of a Novel Omalizumab Solution for Injection Compared with the Standard Lyophilized Powder Formulation. J Bioequiv Availab 3: 144-150.

47. DeMaio W, Kane CP, Nichols AI, Jordan R (2011) Metabolism Studies of Desvenlafaxine. J Bioequiv Availab 3: 151-160.

48. Jawhari D, AISwisi M, Ghannam M (2011) Bioavailability of a New Generic Formulation of Imatinib Mesylate 400mg Tablets Versus Glivec in Healthy Male Adult Volunteers. J Bioequiv Availab 3: 161-164.

49. Polaniak R, Bułdak RJ, Jacheć W, Helewski K, Wojnicz R, et al. (2011) Long-term Exposure to Acetaminophen is a Crucial for Activity of Selected Antioxidative Enzymes and Level of Lipid Peroxidation Process in Rat Liver. J Bioequiv Availab 3: 182-186.

50. Mendes GD, Babadopulos T, Chen LS, Ilha JO, de Almeida Magalhães JC, et al. (2011) The use of Healthy Volunteers to Evaluate Bioequivalence of Antineoplasic Drugs: Pilot Studies with Capecitabine. J Bioequiv Availab S1-005.

51. Zhu W, Masaki T, Cheung AK, Kern SE (2009) In-vitro Release of Rapamycin from a Thermosensitive Polymer for the Inhibition of Vascular Smooth Muscle Cell Proliferation. J Bioequiv Availab 1: 3-12

52. Shakeel F, Ramadan W, Shafiq S (2009) Solubility and Dissolution Improvement of Aceclofenac using Different Nanocarriers. J Bioequiv Availab 1: 39-43.

53. Hawthorne KM, Morris J, Hotze T, Hirschi KD, Abrams SA (2009) Biotechnologically-modified Carrots: Calcium Absorption Relative to Milk. J Bioequiv Availab 1: 34-38.

54. Riju A, Sithara K, Nair SS, Shamina A, Eapen SJ (2009) In Silico Screening Major Spice Phytochemicals for their Novel Biological Activity and Pharmacological Fitness. J Bioequiv Availab 1: 63-73.

55. Griffi ni P, James AD, Roberts AD, Pellegatti M (2010) Metabolites in Safety Testing: Issues and Approaches to the Safety Evaluation of Human Metabolites in a Drug that is Extensively Metabolized. J Drug Metabol Toxicol 1:102.

56. Kanfer I (2010) Strategies for the Bioequivalence Assessment of Topical Dermatological Dosage Forms. J Bioequiv Availab 2: 102-110.

57. Parikh A,Wyant T, Scholz C, Mould DR, Ponich T, et al. (2011) Vedolizumab for the treatment of active ulcerative colitis: A randomized controlled phase 2 dose-ranging study. Inflamm Bowel Dis.

58. Legette L,Reed RL, Miranda CL, Christensen JM,Stevens JF, et al. (2011) Pharmacokinetics of xanthohumol and metabolites in rats after oral and intravenous administration. Mol Nutr Food Res.
59. Takahashi N, Miura M, Niioka T, Sawada K (2011) Influence of H2-recepto antagonists and proton pump inhibitors on dasatinib pharmacokinetics in Japanese leukemia patients. Cancer Chemother Pharmacol.

60. Wood PL, Smith T, Lane N, Khan MA, Ehrmantraut G, et al.(2011) Ora bioavailability of the ether lipid plasmalogen precursor, PPI-1011, in the rabbit: a new therapeutic strategy for Alzheimer's disease. Lipids Health Dis 10: 227.

61. Araki K, Kitagawa K, Mukohara T, Kodama K, Narabayashi M, et al. (2011) First clinical pharmacokinetic dose-escalation study of sagopilone, a novel, fully synthetic epothilone, in Japanese patients with refractory solid tumors. Invest New Drugs.

62. McDonald S, Clements JN (2011) Dalfampridine: A new agent for symptomatic management of multiple sclerosis. Am J Health Syst Pharm 68: 2335-2340.

63. López Gamboa M, Canales Gómez JS, Sandoval TJC, Tovar EN, Mejía MA et al. (2010) Bioavailability of Long Acting Capsules of Melatonin in Mexican Healthy Volunteers. J Bioequiv Availab 2: 116-119.

64. Zakeri-Milani P, Ghanbarzadeh S, Lotfi poor F, Milani M, Valizadeh H (2010) Pharmacokinetic Study of Two Macrolide Antibiotic Oral Suspensions Using an Optimized Bioassay Procedure. J Bioequiv Availab 2: 111-115.

65. http://en.wikipedia.org/wiki/Transdermal

66. Setiawati E, Deniati SH, Yunaidi DA, Handayani LR, Harinanto G, et al. (2009) Bioequivalence Study with Two Naproxen Sodium Tablet Formulations in Healthy Subjects. J Bioequiv Availab1: 28-33.

67. Reichen J, Stickel F, Bhattacharya I, Matschke K, Maller E, et al. (2011) Repeat-dose sirolimus pharmacokinetics and pharmacodynamics in patients with hepatic allografts. Eur J Clin Pharmacol.

68. Song HH, Choi KS, Kim CW, Kwon YE (2009) Pharmacokinetic Profiles of Two Branded Formulations of Piroxicam $20 \mathrm{mg}$ in Healthy Korean Volunteers by Rapid Isocratic HPLC Method. J Bioequiv Availab 1: 74-79.

69. Zhou XL, He JT, Du HJ, Fan YY, Wang Y et al. (2011) Pharmacokinetic and pharmacodynamic profiles of recombinant human erythropoietin-loaded poly(lactic-co-glycolic acid) microspheres in rats. Acta Pharmacol Sin.

70. Lissy M, Ode M, Roth K (2011) Comparison of the pharmacokinetic and pharmacodynamic profiles of one US-marketed and two European-marketed epoetin alfas: a randomized prospective study. Drugs R D 11: 61-75.

71. Cook CS (2011) Current Issues on Bioavailability and Bioequivalence Determination. J Bioequiv Availab S1-003.

72. Colombo D, Egan CG (2010) Bioavailability of Sandimmun® versus Sandimmun

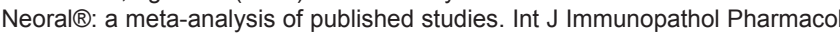
23:1177-1183.

73. Di L, Fish PV, Mano T (2011) Bridging solubility between drug discovery and development. Drug Discov Today.

74. Moreno RA, Sverdloff CE, Oliveira RA, Oliveira SE, Borges DC, et al. (2009) Comparative bioavailability and pharmacodynamic aspects of cyclobenzaprine and caffeine in healthy subjects and the effect on drowsiness intensity. J Bioequiv Availab 1: 86-92.

75. http://www.medindia.net/doctors/drug_information/home.asp 